06

\title{
Влияние плазменной модификации поверхности и стерилизации на оптические характеристики трековых мембран из полиэтилентерефталата
}

\author{
(C) Е.О. Филиппова, В.И. Корепанов, В.Ф. Пичугин \\ Томский политехнический университет, \\ 634050 Томск, Россия \\ e-mail: katerinabosix@mail.ru \\ Поступило в Редакцию 3 октября 2019 г. \\ В окончательной редакции 3 октября 2019 г. \\ Принято к публикации 21 октября 2019 г.
}

\begin{abstract}
Приведены сведения о влиянии плазменной модификации поверхности и процессов стерилизации на оптические характеристики трековой мембраны (ТМ) из полиэтилентерефталата (ПЭТФ). ТМ были получены путем облучения ПЭТФ пучком ионов ${ }^{40} \mathrm{Ar}^{+8}$ и травления в $1.5 \mathrm{M}$ растворе $\mathrm{NaOH}$. Модификация ТМ проведена низкотемпературной плазмой, стерилизация - путем автоклавирования и гамма-излучением. ТМ из ПЭТФ характеризуются относительно низкой пропускающей и преломляющей способностями, что связано с появлением в ПЭТФ неоднородностей структуры, а также кристаллической структуры полимера. Воздействие плазмы и стерилизации уменьшило пропускающую способность ТМ, связанную с увеличением степени кристалличности и образованием артефактов мембраны.
\end{abstract}

Ключевые слова: трековая мембрана, полиэтилентерефталат, стерилизация, низкотемпературная атмосферная плазма, коэффициент пропускания.

DOI: $10.21883 / J T F .2020 .04 .49093 .325-19$

\section{Введение}

Трековая мембрана (ТМ) из полиэтилентерефталата (ПЭТФ) хорошо себя зарекомендовала как материал, использующийся в хирургии глаукомы [1] и имеющий большой потенциал в хирургии роговицы [2,3]. Поверхность будущего кератоимплантата на основе трековой мембраны должна обладать высокими значениями гидрофильности и поверхностной энергии. Однако поверхность ТМ на основе ПЭТФ обладает гидрофобными свойствами и небольшим значением поверхностной энергии $\left(\sim 32 \mathrm{~mJ} / \mathrm{m}^{2}\right)$. Одним из способов улучшения указанных параметров является воздействие атмосферной низкотемпературной плазмы. Преимуществом плазменной обработки является малая глубина проникновения ее частиц в материал без значительной тепловой нагрузки [4-6]. Известно, что воздействие на поверхность ряда органических материалов, полипропилена, политерефталата, а также непредельных каучуков, азотной или азотсодержащей плазмой приводит к образованию азотсодержащих групп в поверхностном слое полимера, что повышает биосовместимость поверхности, а также увеличивает смачиваемость, сохраняющуюся в течение длительного времени [4-6].

Медицинские имплантаты в обязательном порядке подвергаются процедуре стерилизации ионизирующим излучением или автоклавированием [7].

Мембраны, как кератоимплантанты, должны обладать высокими оптическими свойствами: светопропусканием, отсутствием рассеяния света и другими. Однако моди- фикация в плазме и стерилизация могут привести к деградации оптических свойств и ограничить применение материала в медицине.

Цель настоящей работы - исследование влияния плазменной модификации поверхности и процессов стерилизации на оптические характеристики ТМ из ПЭТФ.

\section{1. Материалы и методы исследования}

ТМ из ПЭТФ были получены облучением полимерной пленки пучком ионов $40 \mathrm{Ar}^{+8}$ с максимальной энергией $41 \mathrm{MeV}$ и последующим химическим травлением в $1.5 \mathrm{M}$ растворе $\mathrm{NaOH}$ при температуре $72-82^{\circ} \mathrm{C}$.

Модификация поверхности ТМ проводилась низкотемпературной плазмой атмосферного давления со следующими параметрами: мощность - $2 \mathrm{~W} / \mathrm{cm}^{2}$, частота $5 \mathrm{kHz}$, температура поверхности $-40^{\circ} \mathrm{C}$, скорость потока воздуха - 11/min, время воздействия плазмы 30, 60, $90 \mathrm{~s}$ [8].

Стерилизация паром производилась с помощью парового автоматического стерилизатора ГПа-10 ПЗ в двух режимах: $130-132^{\circ} \mathrm{C}$ при давлении $0.2 \mathrm{MPa}-5 \mathrm{~min}$; $120-121^{\circ} \mathrm{C}$ при давлении $0.11 \mathrm{MPa}-20 \mathrm{~min}$. Время и режимы автоклавирования нормированы согласно ГОСТ Р ИСО 13683-2000.

Для лучевой стерилизации трековых мембран использовалось гамма-излучение радионуклида ${ }^{60} \mathrm{Co}$, проведенное на установке „Исследователь“ с цилиндрической рабочей камерой. Использовались два уровня воздействия $\gamma$-излучения $-1 \mathrm{kGy}(\mathrm{Si})$ и $10 \mathrm{kGy}(\mathrm{Si})$, что 
соответствует нижнему и верхнему пределам диапазона доз, используемых при стерилизации ионизирующим излучением.

После обработки ТМ проводилось комплексное исследование мембран: топография поверхности, спектры ИКпоглощения, степень кристалличности, их оптические свойства (коэффициент преломления $n(\lambda)$, коэффициент пропускания $\tau(\lambda)$. Коэффициент преломления $n(\lambda)$ определялся по методике, описанной в работах $[9,10]$.

Топография поверхности исследовалась на комплексном корреляторе оптических, спектральных и топографических свойств поверхности объектов „Centaur HR“ и микроскопе Hitachi S3400N Type II. Профиль шероховатости поверхности строился с точностью до $1 \mathrm{~nm}$ в программе Gwyddion. Расчет параметров шероховатости, описывающих топографию поверхности, проводился согласно ГОСТ 2789-73 и ISO 4287:1997. Для количественной оценки шероховатости поверхности использовались трехмерные параметры $S_{a}, S_{q}$, где $S_{a}$ - среднее арифметическое отклонение поверхности (средняя высота по 3D-зоне); $S_{q}$ - среднеквадратичное отклонение поверхности от базовой плоскости.

Для определения степени кристалличности полимера была проведена дифференциальная сканирующая калориметрия на совмещенном ТГА/ДСКА анализаторе SDT Q600. Расчет степени кристалличности проводился согласно методики, представленной в [11]. Измерения ИК - спектров ТМ производились с помощью ИК фурье-спектрометра Nicolet 5700.

Спектры пропускания и поглощения ТМ в видимой области были измерены с помощью спектрофотометра СФ-256УВИ (Россия) в диапазоне длин волн (380-1000) nm. Для уменьшения влияния неоднородности ТМ и приближения к реальным условиям эксплуатации образцы помещались на внутреннюю стенку кюветы, заполненной выделенной в асептических условиях ex temporo внутриглазной жидкостью кроликов породы Шиншилла.

\section{2. Результаты и их обсуждение}

На рис. 1 представлены спектры пропускания исходных ТМ и ТМ после плазменной обработки. Согласно полученным данным, коэффициент коллимированного пропускания $\tau(\lambda)$ исходных ТМ находится в пределах 40-44.2\%. Плазменная обработка приводит к уменьшению коэффициента коллимированного пропускания ТМ на 2-5\%. В спектрах пропускания при $\lambda>620 \mathrm{~nm}$ видна характерная колебательная структура пропускания, обусловленная интерференционными явлениями ТМ (рис. 1).

Для успешного использования полимеров в качестве оптических сред в хирургии роговицы необходимо значение коэффициента преломления $n$, равное 1.5 [12]. Повышение преломляющей способности материала достигается тем, что в мономеры полимера вводят эле-

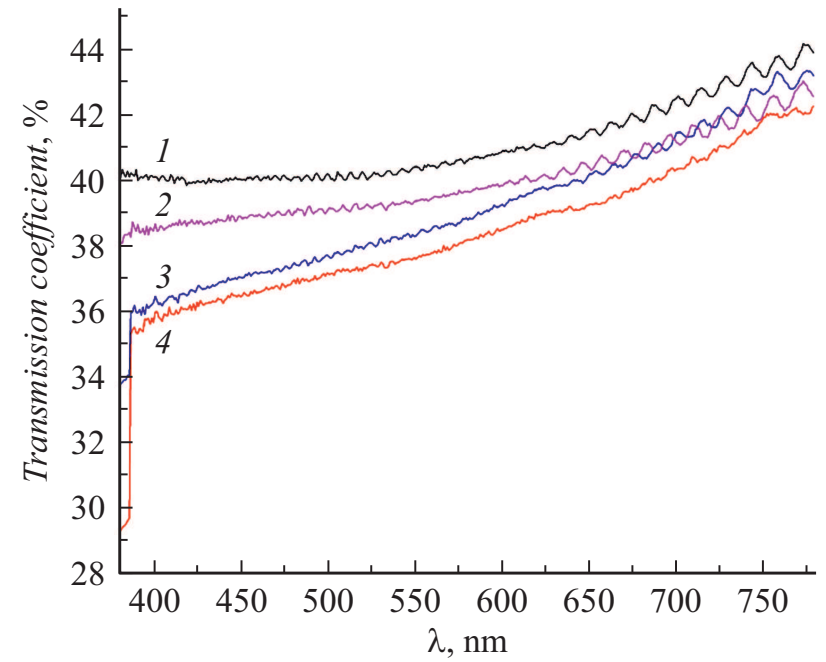

Рис. 1. Спектр пропускания трековых мембран после плазменной обработки: 1 - исходные мембраны, 2 - после плазменной обработки $(30 \mathrm{~s}), 3$ - после плазменной обработки $(60 \mathrm{~s}), 4$ - после плазменной обработки (90s).

менты с высокой молекулярной рефракцией, такие как ароматические соединения, карбоксильные группы, соединения $\mathrm{Br}, \mathrm{Cl}$ [13]. На значение показателя преломления может оказывать влияние также оптическая неоднородность материала [12]. В случае волновых аббераций, обусловленных неоднородностью структуры, термоупругими напряжениями, свилями (прозрачными дефектами) вещества, показатель преломления пленок ПЭТФ приобретает неоднородный характер и имеет невысокие значения [12].

Показатель преломления ТМ, определенный нами из оптических измерений по методике, представленной в $[9,10]$, до и после плазменной обработки при всех значениях $\lambda$ оказался равным $n=1.255 \pm 0.1$, т. е. относительно низкое значение по сравнению с пленкой ПЭТФ, у которой $n=1.6$ [12-14]. Это, по-видимому, связано с появлением в пленке ПЭТФ в процессе создания мембраны неоднородностей структуры в виде пор и свилей. На рис. 2 представлено электронномикроскопическое изображение элемента ТМ из ПЭТФ, где видны достаточно равномерно распределенные по поверхности поры со средним диаметром $0.5 \mu \mathrm{m}$ и поверхностной плотностью $5 \cdot 10^{8} \mathrm{~cm}^{-2}$. Сечение ТМ, представленное на рис. 2, $b$, иллюстрирует цилиндрическую форму сквозных пор.

Топография поверхности мембраны играет особую роль при ее взаимодействии с живой тканью и во многом определяет оптические характеристики ТМ. Расчеты параметров шероховатости показали значительное (в 9 раз) увеличение параметров ТМ при плазменной обработке как результат образования артефактов в виде многочисленных хаотично распределенных мелких неровностей конусообразной формы высотой более $100 \mathrm{~nm}$ (рис. 3). Плотность таких образований 

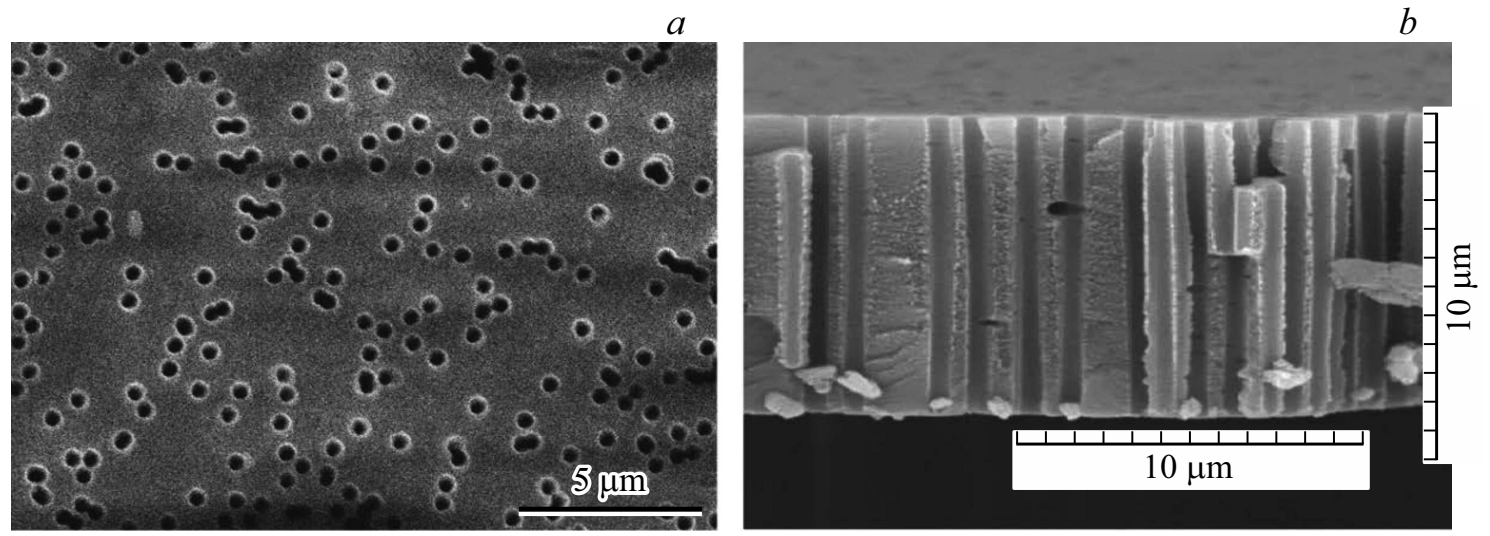

Рис. 2. Электронно-микроскопическое изображение трековой мембраны: $a-$ поверхность трековой мембраны, $b-$ скол трековой мембраны.
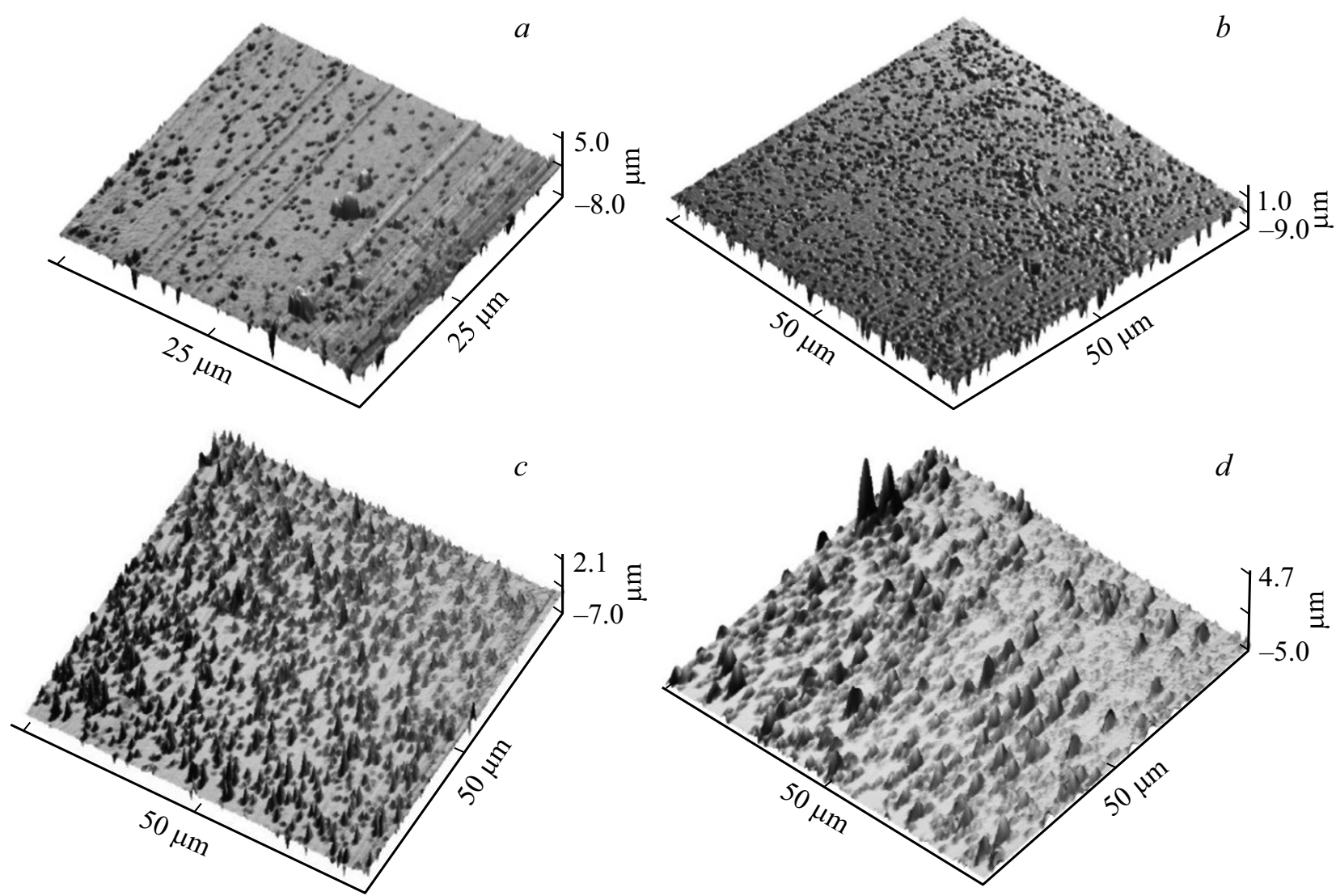

Рис. 3. Топография поверхности трековых мембран исходных $(a)$, после плазменной модификации: время обработки $30(b), 60(c)$, 90s (d).

достигает $2.43 \mu \mathrm{m}^{-2}$ при времени воздействия плазмы в течение $30 \mathrm{~s}$.

Среднее значение параметра шероховатости $S_{a}$ исходных ТМ составляет $0.03 \mu \mathrm{m}$. Плазменная обработка ТМ приводит к дальнейшему увеличению параметра шероховатости поверхности $S_{a}$ в 9 раз, составив $0.28 \mu \mathrm{m}$.

Развитие рельефа поверхности после плазменной обработки с увеличением ее параметров шероховатости способствует снижению коэффициента коллимированного пропускания ТМ.

Плазменная обработка влияет также на кристаллизацию материала. Степень кристалличности исходной ТМ составила 4191\%, после плазменной обработки в течение $30 \mathrm{~s}-43.55 \%$. Образование кристаллического состояния полимера зависит от способности полимерных молекул выстраиваться в упорядоченные структуры [15]. 


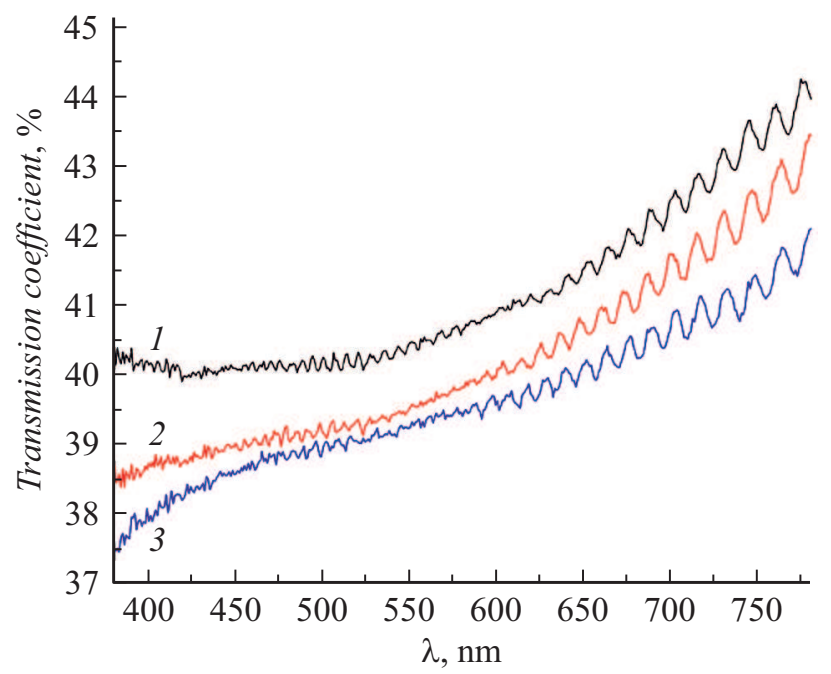

Рис. 4. Спектр пропускания ТМ: 1 - исходная мембрана, 2 - после $\gamma$-стерилизации (доза облучения $1 \mathrm{kGy}), 3$ - после $\gamma$-стерилизации (доза облучения $10 \mathrm{kGy}$ ).

При кристаллизации полимера образуются анизотропные структуры - сферолиты, размером более $100 \mathrm{~nm}$, вносящие основной вклад в рассеяние света и являющиеся одной из главных причин недостаточности прозрачности материала $[12,16]$. Интенсивность рассеянного света снижается с уменьшением степени кристалличности и среднего размера сферолитов. Таким образом, возможное образование сферолитов в структуре полимера в результате плазменной обработки также способствует снижению коэффициента пропускания $\tau(\lambda)$.

Показатель преломления и показатель поглощения, как оптические постоянные, входят в число фундаментальных характеристик вещества наряду с химическим составом, плотностью полимера, и напрямую зависят от изменения состава или структуры материала [18-23]. Так, полимеры, в структуре которых превалируют карбоксильные группы, имеют больший коэффициент поглощения в области, близкой к УФ части спектра [18].

Измерения ИК спектров свидетельствует о том, что воздействие плазмы приводит к уменьшению амплитуды полос поглощения ТМ при 1712, 1241 и $1093 \mathrm{~cm}^{-1}$, которые связаны с неполярными $(\mathrm{C}=\mathrm{C}, \mathrm{C}=\mathrm{O})$ функциональными группами в приповерхностном слое мембраны. Таким образом, результаты ИК спектроскопии свидетельствуют об уменьшении количества неполярных (гидрофобных) функциональных групп $(\mathrm{C}=\mathrm{C}, \mathrm{C}=\mathrm{O})$ после воздействия низкотемпературной плазмы. Предположительно, воздействие плазмы способствует деструкции полимерных цепей поверхности ТМ, находящихся в аморфной фазе, формировании в местах разрыва связей $\mathrm{C}-\mathrm{O}-$ и $\mathrm{C}-\mathrm{C}-г$ рупп [8]. Это сказывается на увеличении шероховатости материала и снижению коэффициента коллимированного пропускания $t(\lambda)$.

Коэффициент коллимированного пропускания ТМ после стерилизации $\gamma$-квантами ${ }^{60}$ Со спектра видимого излучения находится в пределах $37-43 \%$, что в среднем на $3 \%$ меньше $t(\lambda)$ исходных мембран (рис. 4). Вид спектральных кривых $t(\lambda)$ зависит от дозы облучения [17]: с увеличением дозы уменьшаются значения $t(\lambda)$, причем наибольшее влияние дозы на вид кривых отмечено ближе к красной области спектра (рис. 4).

Коэффициент коллимированного пропускания ТМ после паровой стерилизации находится в пределах $37.5-42 \%$ при режиме стерилизации (стерилизация при $120-121^{\circ} \mathrm{C}$ ) и $39.9-42.5 \%$ (стерилизация при $\left.130-132^{\circ} \mathrm{C}\right)$. Интерференционная картина коэффициента пропускания ТМ после автоклавирования как и в случае с мембранами после $\gamma$-стерилизации наблюдалась при $\lambda=580 \mathrm{~nm}$.

Результаты растровой электронной микроскопии и атомно-силовой микроскопии показали появление на поверхности ТМ артефактов овальной формы высотой $(300-400) \mathrm{nm}$, средним диаметром $3.0 \mu \mathrm{m}$, плотностью $0.007 \mu \mathrm{m}^{-2}$, в результате паровой стерилизации, и дефектов неправильной формы глубиной (3.5-4.0) $\mu \mathrm{m}$ в результате $\gamma$-облучения (рис. 5).
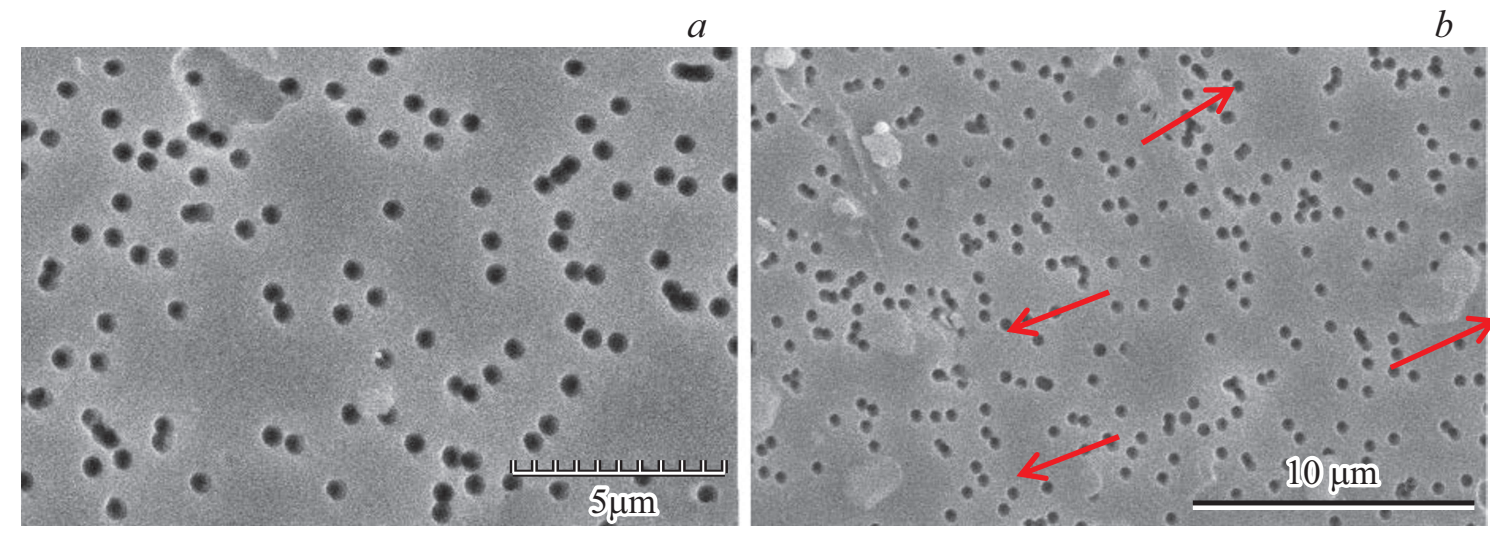

Рис. 5. Электронно-микроскопическое изображение поверхности ТМ после стерилизации $\gamma$-излучением дозой $1 \mathrm{kGy}(b)$ и паровой стерилизации $\left(T=120^{\circ} \mathrm{C}\right)$. 
Средние значения параметров шероховатости трековых мембран до и после стерилизации

\begin{tabular}{l|l|l}
\hline Образец ТМ & \multicolumn{1}{|c|}{$S_{a}, \mu \mathrm{m}$} & \multicolumn{1}{|c}{$S_{q}, \mu_{m}$} \\
\hline Исходная & 0.03 & 0.0375 \\
Плазма30 & $0.1 ; p<0.0001$ & $0.2 ; p<0.0001$ \\
Гамма 1 kGy & $0.03 ; p>0.05$ & $0.05 ; p>0.05$ \\
Гамма 10 kGy & $0.03 ; p>0.05$ & $0.05 ; p>0.05$ \\
Пар120 & $0.05 ; p<0.002$ & $0.09 ; p<0.02$ \\
Пар130 & $0.06 ; p<0.01$ & $0.1 ; p<0.02$
\end{tabular}

Примечание. Пар120, Пар130 - после паровой стерилизации при $T=120^{\circ} \mathrm{C}(P=0.11 \mathrm{MPa})$ и $T=130^{\circ} \mathrm{C}(P=0.2 \mathrm{MPa})$ соответственно; Плазма30 - после плазменной модификации поверхности; Гамма $1,10 \mathrm{kGy}-$ после $\gamma$-стерилизации в дозе 1 и $10 \mathrm{kGy}$ соответственно. Приведенные данные - средние величины; $p$ - уровень статистической значимости различий по сравнению с исходными мембранами.

Расчеты параметров шероховатости показали, что воздействие $\gamma$-лучей на исходную ТМ не оказывает существенного влияния на значение $S_{a}$ в отличие от плазменной обработки (см. таблицу). Паровая стерилизация увеличивает значение $S_{a}$ на $40 \%$ по сравнению с исходными образцами $(p<0.05)$.

Степень кристалличности ТМ из ПЭТФ после паровой стерилизации составляет $41.71 \%$, после $\gamma$ стерилизации - $43.71 \%$, что на $2 \%$ больше кристалличности исходных мембран.

Полученные результаты свидетельствуют о заметном влиянии $\gamma$-лучей на кристалличность ТМ в отличие от паровой стерилизации, которая вносит вклад только в изменение поверхностных свойств ТМ без вовлечения структуры полимера в целом. Механизм подобного $\gamma$ воздействия связан с разрывом связей полимера с последующей перестройкой цепей и укладывании их в более упорядоченную кристаллическую структуру, что являлось причиной снижения коэффициента коллимированного пропускания ТМ $(\lambda)$ мембран. Механизм воздействия паровой стерилизации на оптические свойства ТМ связан в первую очередь с образованием овальных артефактов на поверхности мембраны, являющиеся следствием деформации тонкой пленки под действием горячего пара.

\section{Выводы}

ТМ из ПЭТФ характеризуются относительно низким светопропусканием $(\tau(\lambda)$ находится в пределах $40-44.2 \%)$ и низкой преломляющей способностями, что связано с появлением в пленке ПЭТФ в процессе создания мембраны неоднородностей структуры в виде пор и свилей, а также кристаллической структуры полимера.

Воздействие плазмы способствует деструкции полимерных цепей поверхности ТМ, находящиеся в аморфной фазе, формировании в местах разрыва связей $\mathrm{C}-\mathrm{O}-$ и C-C-карбоксильных групп, что сказывается на увели- чении шероховатости материала, снижении коэффициента пропускания на $(2-5) \%$.

Стерилизация способствует уменьшению пропускающей способности и увеличению показателя преломления ТМ из ПЭТФ, что связано в случае с $\gamma$-облучением - с разрывом связей полимера с последующей перестройкой цепей и укладывании их в более упорядоченную кристаллическую структуру, в отношении парового метода - с образованием артефактов в виде овальных выступов на поверхности мембраны, являющиеся иллюстрацией деформации тонкой пленки под действием горячего пара.

\section{Финансирование работы}

Работа выполнена при финансовой поддержке Министерства образования и науки РФ, Федеральной целевой программы (соглашение № 14.575.21.0140, уникальный идентификатор RFMEFI57517X0140).

\section{Конфликт интересов}

Авторы заявляют, что у них нет конфликта интересов.

\section{Список литературы}

[1] Рязанцева Т.В., Кравеи, Л.И., Елинсон В.М. // Перспективные материалы. 2012. № 3. С. 41-51.

[2] Филиппова Е.О., Кривошеина О.И., Запускалов И.В. // Медицинский вестник Башкортостана. 2015. Т. 10. № 2. C. 137-139.

[3] Filippova E.O., Pichugin V.F., Sokhoreva V.V. // Petroleum Chemistry. 2014. Vol. 54. N 8. P. 669-672.

[4] Navaneetha Pandiyaraj K., Selvarajan V., Deshmukh R.R., Changyou Gao // Vacuum. 2009. Vol. 83. P. 332-339.

[5] Chiper A., Apetroaiei N., Popa G. // J. Optoelectron. Advan. Mater. 2005. N 7(5). P. 2561-2570.

[6] Nastuta A.V., Rusu G.B., Topala I., Chiper A.S., Popa G. // J. Optoelectron. Advan. Mater. 2008. Vol. 10. N 8. P. 2038 2042.

[7] Subhashini Govindaraj, Meenakshi Sundaram Muthuraman // Intern. J. Chem. Tech. Research. 2015. Vol. 8. N 2. P. 897-911.

[8] Филипnова E.О., Карпов Д.А., Градобоев А.В., Сохорева В.В., Пичугин В.Ф. // Перспективные материалы. 2016. № 5. C. 1-13.

[9] Брус В.В., Ковалюк З.Д., Марьянчук П.Д. // ЖТФ. 2012. Т. 82. Вып. 8. С. 110-113.

[10] Брус В.В., Солован М.Н., Майструк Э.В., Козярский И.П. // ФТТ. 2014. Т. 56. Вып. 10. С. 1886-1890.

[11] Новак А.В., Новак В.Р. // Письма в ЖТФ. 2013. Т. 39. Вып. 19. С. 32-40.

[12] Серова В.Н. Полимерные оптические материалы. СПб.: Научные основы и технологии, 2011. 284 с. 
[13] Ван Кревелен Д.В. Свойства и химическое строение полимеров. М.: Химия, 1976. 416 с.

[14] Зуев Б.М., Утэй Б.И., Чистяков Е.В. // Высокомолекулярные соединения. 1980. Т. 22. № 7. С. 1523-1528.

[15] Odian George. Principles of Polymerization. NY.: John Wiley \& Sons, 1991. $839 \mathrm{p}$.

[16] Сперантская Т.А., Тарупина Л.И. Оптические свойства полимеров. Л.: Химия, 1976. $136 \mathrm{c.}$

[17] Митрофбанов А.В., Карбань О.В., Сугоняко А., Любомска М. // Поверхность. Рентгеновские, синхротронные и нейтронные исследования. 2009. № 7. С. 30-38. 